\title{
Design of a PID Controller for a Linearized Magnetic Bearing
}

\author{
Theodore K. Psonis, ${ }^{1}$ Pantelis G. Nikolakopoulos, ${ }^{2}$ and Epaminondas Mitronikas ${ }^{1}$ \\ ${ }^{1}$ Laboratory of Electromechanical Energy Conversion, Department of Computer and Electrical Engineering, University of Patras, \\ Rio, 26500 Patras, Greece \\ ${ }^{2}$ Machine Design Laboratory, Department of Mechanical and Aeronautics Engineering, University of Patras, Rio, 26500 Patras, Greece
}

Correspondence should be addressed to Pantelis G. Nikolakopoulos; pnikolak@mech.upatras.gr

Received 12 June 2015; Revised 11 September 2015; Accepted 15 September 2015

Academic Editor: Luis San Andres

Copyright (C) 2015 Theodore K. Psonis et al. This is an open access article distributed under the Creative Commons Attribution License, which permits unrestricted use, distribution, and reproduction in any medium, provided the original work is properly cited.

\begin{abstract}
This paper presents the study of magnetic bearings regarding a linear model. Initially, the advantages of magnetic bearings are referenced, in relation to the existing technology. Subsequently, the linearized model of the system is presented and the need for closed loop and control of the system is clarified. This need leads to further analysis of linear controllers like P, I, D, PI, PD, and PID. For each of them, the stability of closed loop system is studied, using the characteristic equation of the system and the RouthHurwitz criterion. To this end, the boundary conditions for the existence of the stability of each of them are found and presented. After finding the controllers' characteristic parameters which could provide stability to the system, simulation tests with existence of white noise follow. Finally, the proposed PID controller performance is examined, based on existing laboratory data, and results concerning the stability of this controller are presented.
\end{abstract}

\section{Introduction}

Magnetic bearings are an improved type of bearings which promise to replace the conventional bearings technology like ball or oil film lubricated bearings. This new technology offers many advantages. The absence of contact between the bearing and the rotor makes it ideal to be used in vacuum applications and sterile clean rooms. Without friction between the shaft and the bearing higher speeds can be attained, up to yield strength of the shaft. Because of the absence of the lubrication seals, the dimensions and limits of strength can be changed, allowing the use of larger and more stiff shaft. Increasing the stiffness of the shaft offers many advantages and solutions to the problems occurring at high speeds as well as those coming from vibrations. Problems such as vibration isolation and the ability of the system to exceed critical speeds while being resistant to external shocks can be improved. Finally, the most powerful advantage is the lack of mechanical wear. This has resulted in lower maintenance costs and longer life of the shaft. The advantages of this new technology are not just limited only on the bearings but are spreading to the motors that could work with these new bearings. These motors can have smaller shaft length. This will make the existence of a higher critical speed possible, while at the same time contributing to stable operation of the motor. In the early design of compressors and turbines, it was of great importance to locate the rotor critical speeds so as to insure that a turbo rotor would not be operating at a critical speed. This has to do with the stiffness and damping coefficients that simulate the oil film behavior and further affect the dynamic of the rotor-bearing system [1]. A lot of work has been done regarding the stiffness and damping coefficients determination, showing the importance of this topic [2]. All of these advantages have contributed to the further study of magnetic bearings [3-6]. Although the active magnetic bearings have a lot of advantages as described above, when coming to their dynamics researchers found that they are hard to be mastered. Also it is difficult to get their precise mathematical model. Furthermore, the PID method is less relying on the mathematical model regarding the control issue. So, PID control is used for the control of the magnetic levitation systems. However, because the general PID controllers always have only one couple of constant parameters, it is difficult some times to meet the need of control performances. That is why nonlinear control strategies have been also developed. PID control schemes 
were presented by the authors in $[3,5,6]$. They presented the advantages of the use of the linear magnetic bearing models in combination with PID control laws. These studies have contributed to the further investigation of the magnetic bearing and to the improvement of it. Farmakopoulos et al. [7] presented PID models regarding a linear active magnetic bearing and a hybrid magnetic bearing. They also presented the limits of the stability of the proposed controllers.

A variation on the conventional PID control is a cascaded $\mathrm{PI} / \mathrm{PD}$ position control as presented in [8]. The advantages of the PI/PD control are transparent design, simple realization, and a higher closed loop damping and stiffness in comparison with the conventional PID control.

The application of $H_{\infty}$ optimal control design to AMBs began soon after the introduction of $H_{\infty}$ control theory by Zames [9] in 1981. An important requirement in most practical AMB applications is that the stiffness of the controlled system, when subjected to unknown dynamic disturbance forces or loads, should not be below a given value for some specified frequency range. The new theory was applied by Herzog and Bleuler [10] to synthesize an $H_{\infty}$ control and demonstrate its effectiveness in dealing with "worst case" disturbances within the specified frequency range. In [11], Fujita et al. designed and experimentally tested an $H_{\infty}$ controller for robust stability in the presence of various perturbations and uncertainties in plant parameters for an AMB system with satisfactory results.

A series of papers have been presented regarding the nonlinear control models and stability issues in $[6,12,13]$. The Volterra method is described in [14] while in [15] the LPV control models are also discussed.

In this paper, linear controllers in terms of P, I, D, PI, PD, and PID are analyzed and their stability issues of closed loop system, using the Routh-Hurwitz criterion, are presented. Also, the suitability and the applicability of each of the proposed controllers, in a one-dimensional active magnetic bearing, and its characteristic parameters, are analyzed and discussed. For better harmonization with the real data, our system is disturbed by the presence of white noise. This method is widely accepted in control studies. The noise values vary in a range of $0.001-0.01 \mathrm{~V}$. This helps to better evaluate the linear controllers. A linear control model can be targeted on small perturbations round the equilibrium point of the rotor bearing system, that is why it has some deviations of a nonlinear model. However, many systems operate in linear regions, so the PID control schemes may have a wide range of applications. The goal of this paper is to investigate the control performance of the magnetic bearings under noise disturbances. This is done using a simplified bearing model.

\section{Models and Formulations}

For better understanding and easier analysis, a linearized model which consists of a small shaft and a pair of electromagnets (Figure 1) is used (1D magnetic bearing). The system is at rest and the shaft can be moved between the electromagnets. So, the forces produced by electromagnets should counterbalance the weight of the rotor. The shaft

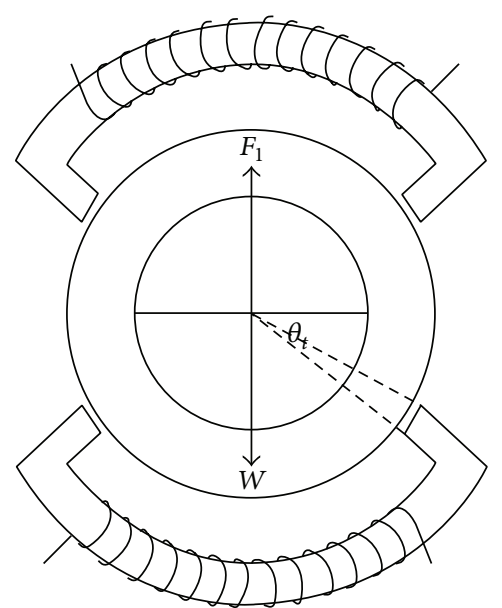

FIGURE 1: A shaft and a pair of electromagnets.

has $5 \mathrm{~cm}$ diameter and $5 \mathrm{~cm}$ length. It is assumed that the mass density of the shaft is $7.9 \mathrm{~g} / \mathrm{cm}^{3}$ for sake of convenient calculations. The number of turns of each pole is 50 and the gap between the shaft and the inner wall of the bearing set is $0.5 \mathrm{~mm}[8,12,13]$.

Below the basic operational characteristics are calculated in order to define and to evaluate the PID control schemes for the described electromechanical system.

(1) The weight of shaft can be calculated as below:

$$
\begin{aligned}
m & =\pi \cdot\left(\frac{5 \mathrm{~cm}}{2}\right)^{2} \cdot 5 \mathrm{~cm} \cdot 7.9 \frac{\mathrm{g}}{\mathrm{cm}^{3}}=0.775 \mathrm{~kg}, \\
|W| & =m \cdot|g|=7.595 \mathrm{~N} .
\end{aligned}
$$

The weight of the rotor has direction that is shown in Figure 1.

(2) Calculation of bias current $\left(I_{\text {bias }}\right)$ is as follows.

At the equilibrium point of the shafts inside the bearing the following equation must be valid:

$$
\begin{aligned}
F_{1}-W & =0 \Longrightarrow I_{\text {bias }}=\sqrt{\frac{(W \cdot 2 \cdot g)}{\left(\left(N^{2} \cdot \mu_{0} \cdot S\right) /(2 \cdot g)\right)},} \\
S & =l \cdot\left(\pi \cdot D \cdot \frac{\theta_{t}}{360}\right)=5.45 \cdot 10^{-4} \mathrm{~m}^{2}, \\
I_{\text {bias }} & =2.1 \mathrm{~A} .
\end{aligned}
$$

For better understanding of the system the block diagram (Figure 2) is shown.

From (2) the following expression is derived:

$$
L_{0}=\frac{N^{2} \cdot \mu_{0} \cdot S}{2 \cdot g}=0.0017121679 \mathrm{H},
$$

where $g$ is gap between shaft and bearing inner wall. $N$ is the number of turns. $L_{0}$ is nominal inductance. $K_{f c f}$ is a force-current factor and N/A is the units of measurement (newton/ampere):

$$
K_{f c f}=\frac{2 \cdot L_{0} \cdot \cos (\pi / p)}{g} \cdot I_{\text {bias }} \text { N/A. }
$$




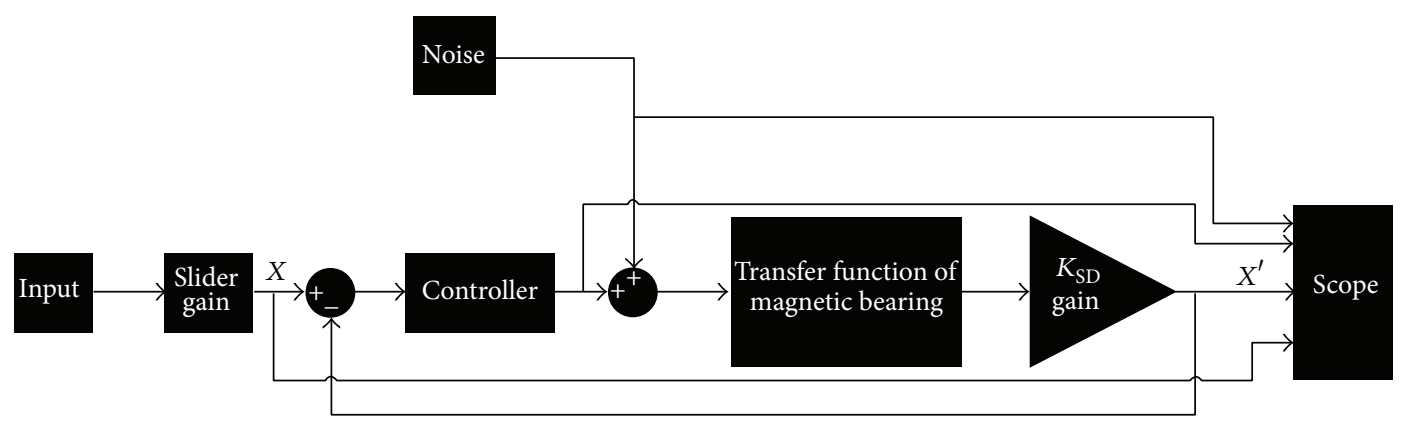

Figure 2: Block diagram of the system.

with $p$ being the number of poles bearing, $W \times l$ the gasketgap magnet shaft, and $k_{x}$ the force-displacement factor.

$$
k_{x}=\frac{2 \cdot L_{0} \cdot \cos (\pi / p)}{g^{2}} \cdot I_{\text {bias }}^{2} \mathrm{~N} / \mathrm{m} .
$$

The transfer function of the magnetic bearing following the Figure 2 can be written as

$$
\frac{K_{f c f}}{m \cdot s^{2}-k_{x}} .
$$

Neglecting unbalance and gyroscopic forces, (7) can be transformed in the Laplace domain, giving the transfer function:

$$
\frac{X^{\prime}(s)}{X(s)}=\frac{K_{f c f}}{m s^{2}-k_{x}} .
$$

The poles of the transfer function that correspond to an unstable system are $S_{1,2}= \pm \sqrt{k_{x} / m}$, and using these poles, the AMB plant is an unstable system.

For this reason a closed loop control scheme is necessary.

\section{Considerations of PID Control}

The closed loop system can be stable in the presence of a controller. In linear models the most common and effective controllers are the P, I, D, PI, PD, and PID. Each of these controllers has its own advantages. These features will be mentioned below.

3.1. Proportional Controller $(P)$. The controller output is proportional to the error, contributes to the reduction of the rise time, and reduces but never eliminates the steady-state error.

3.2. Integral Controller (I). It has as a result the elimination of the permanent fault but deteriorates the transient response.

3.3. Differential Controller (D). It has the effect of increasing the stability of the system by reducing the rise and improving the transient response.

The influence of each controller type in the individual characteristics of the system is shown in Table 1.
TABLE 1: Effect of controllers in the system.

\begin{tabular}{lcccc}
\hline Controller & $\begin{array}{c}\text { Rising } \\
\text { time }\end{array}$ & Rise & $\begin{array}{c}\text { Restoration } \\
\text { time }\end{array}$ & $\begin{array}{c}\text { Permanent } \\
\text { error }\end{array}$ \\
\hline Proportional & Reduction & Increase & $\begin{array}{c}\text { Minor } \\
\text { change }\end{array}$ & Reduction \\
\hline Integral & Reduction & Increase & Increase & Elimination \\
\hline Derivative & $\begin{array}{c}\text { Minor } \\
\text { change }\end{array}$ & Reduction & Reduction & $\begin{array}{c}\text { Minor } \\
\text { change }\end{array}$ \\
\hline
\end{tabular}

3.4. Proportional-Differential Controller (PD). It has as a result the reduction of the rise and the reduction of the restoration time. But it has a little effect on the rise time and the steady-state error.

3.5. Proportional-Integral (PI). It has as a result the elimination of the permanent error and reducing the rising time but greatly increases the restoration time.

3.6. Proportional-Integral-Differential Controller (PID). It has as a result the elimination of the permanent error and the rise. Simultaneously it achieves the reduction of rising and restoration time $[16,17]$.

3.7. Proportional Controller $(P)$. Assuming the existence of proportional control, the system is as follows:

$$
\frac{X}{X^{\prime}}=\frac{K_{\mathrm{P}} \cdot K_{\mathrm{I}}}{m \cdot s^{2}+K_{\mathrm{P}} \cdot K_{\mathrm{I}}-k_{x}} .
$$

To ensure system stability, the gain of the proportional controller must issue the following condition:

$$
\begin{aligned}
K_{\mathrm{P}} \times K_{f c f}-K_{x} & \geq 0 \Longrightarrow \\
K_{\mathrm{P}} & \geq \frac{K_{x}}{K_{f c f}} \Longrightarrow \\
K_{\mathrm{P}} & \geq 8875.1 .
\end{aligned}
$$

3.8. Integral Controller (I). Assuming the existence of Integral control the system is

$$
\frac{X}{X^{\prime}}=\frac{K_{f c f} \times K_{\mathrm{I}}}{m \times s^{3}-K_{x} \times s+K_{f c f} \times K_{\mathrm{I}}} .
$$


The roots of the denominator are

$$
\begin{aligned}
& s_{1} \\
& =\underbrace{\sqrt[3]{-\frac{K_{f c f} \cdot K_{\mathrm{I}}}{2 \cdot m}+\sqrt[2]{\frac{27 \cdot m \cdot K_{f c f}{ }^{2} \cdot K_{\mathrm{I}}^{2}-4 \cdot K_{x}{ }^{3}}{108 \cdot m^{3}}}}}_{A} \\
& +\underbrace{\sqrt[3]{-\frac{K_{f c f} \cdot K_{\mathrm{I}}}{2 \cdot m}-\sqrt[2]{\frac{27 \cdot m \cdot K_{f c f}^{2} \cdot K_{\mathrm{I}}^{2}-4 \cdot K_{x}^{3}}{108 \cdot m^{3}}}}}_{B}, \\
& s_{2}=-\frac{1}{2} \cdot(A+B)+i \cdot \frac{1}{2} \cdot \sqrt{3} \cdot(A-B), \\
& s_{3}=-\frac{1}{2} \cdot(A+B)-i \cdot \frac{1}{2} \cdot \sqrt{3} \cdot(A-B) \text {. }
\end{aligned}
$$

To ensure the stability of the system, the real part of these roots must satisfy the following inequality:

$$
\operatorname{Re}\left\{s_{1,2,3}\right\} \leq 0
$$

The above inequality cannot be satisfied for any value of $K_{i}$. So, integral control of the system is not feasible.

3.9. Differential Controller (D). Assuming the existence of differential controller, the system becomes

$$
\frac{X}{X^{\prime}}=\frac{K_{\mathrm{D}} \cdot K_{f c f} \cdot s}{m \cdot s^{2}+K_{\mathrm{D}} \cdot K_{f c f} \cdot s-K_{x}} .
$$

The roots of the denominator are

$$
\begin{aligned}
& s_{1}=\frac{-K_{\mathrm{D}} \cdot K_{f c f}+\sqrt{\left(K_{\mathrm{D}} \cdot K_{f c f}\right)^{2}+4 \cdot m \cdot K_{f c f}}}{2 \cdot m}, \\
& s_{2}=\frac{-K_{\mathrm{D}} \cdot K_{f c f}-\sqrt{\left(K_{\mathrm{D}} \cdot K_{f c f}\right)^{2}+4 \cdot m \cdot K_{f c f}}}{2 \cdot m} .
\end{aligned}
$$

To ensure the stability of the system, the real part of these roots must satisfy the following inequality:

$$
\operatorname{Re}\left\{s_{1,2}\right\} \leq 0
$$

The above inequality cannot be satisfied for any value of $K_{\mathrm{D}}$. So, differential control for our system is not possible.

3.10. Proportional-Integral Controller (PI). Assuming the existence of proportional-integral controller the system becomes

$$
\frac{X}{X^{\prime}}=\frac{K_{f c f} \cdot\left(K_{\mathrm{I}}+s \cdot K_{\mathrm{P}}\right)}{m \cdot s^{3}+\left(K_{f c f} \cdot K_{\mathrm{P}}-K_{x}\right) \cdot s+K_{f c f} \cdot K_{\mathrm{I}}}
$$

The roots of the denominator are

$$
\begin{aligned}
& s_{1}=\underbrace{\sqrt[3]{-\frac{K_{f c f} \cdot K_{\mathrm{I}}}{2 \cdot m}+\sqrt[2]{\left(\frac{K_{f c f} \cdot K_{\mathrm{P}}-K_{x}}{3 \cdot m}\right)^{3}+\left(\frac{K_{f c f} \cdot K_{\mathrm{I}}}{2 \cdot m}\right)^{2}}}}_{C} \\
& +\underbrace{\sqrt[3]{-\frac{K_{f c f} \cdot K_{\mathrm{I}}}{2 \cdot m}-\sqrt[2]{\left(\frac{K_{f c f} \cdot K_{\mathrm{P}}-K_{x}}{3 \cdot m}\right)^{3}+\left(\frac{K_{f c f} \cdot K_{\mathrm{I}}}{2 \cdot m}\right)^{2}}}}_{D}, \\
& s_{2}=-\frac{1}{2} \cdot(C+D)+i \cdot \frac{1}{2} \cdot \sqrt{3} \cdot(C-D), \\
& s_{3}=-\frac{1}{2} \cdot(C+D)-i \cdot \frac{1}{2} \cdot \sqrt{3} \cdot(C-D) .
\end{aligned}
$$

To ensure the stability of the system, the real part of these roots must satisfy the following condition:

$$
\operatorname{Re}\left\{s_{1,2,3}\right\} \leq 0 .
$$

The above inequality is not satisfied for any value of $K_{i}, K_{\mathrm{P}}$.

So, a stable proportional-integral controller is not feasible for the entire system.

3.11. Proportional-Differential Controller (PD). Assuming the existence of proportional-differential controller the system is the following:

$$
\frac{X}{X^{\prime}}=\frac{\left(K_{\mathrm{D}} \cdot s+K_{\mathrm{P}}\right) \cdot K_{f c f}}{m \cdot s^{2}+K_{f c f} \cdot K_{\mathrm{D}} \cdot s+K_{\mathrm{P}} \cdot K_{f c f}-K_{x}} .
$$

The roots of the denominator are

$s_{1}$

$$
=\frac{-K_{f c f} \cdot K_{\mathrm{D}}+\sqrt{\left(K_{f c f} \cdot K_{\mathrm{D}}\right)^{2}-4 \cdot\left(K_{f c f} \cdot K_{\mathrm{P}}-K_{x}\right) \cdot m}}{2 \cdot m},
$$

$$
=\frac{-K_{f c f} \cdot K_{\mathrm{D}}-\sqrt{\left(K_{f c f} \cdot K_{\mathrm{D}}\right)^{2}-4 \cdot\left(K_{f c f} \cdot K_{\mathrm{P}}-K_{x}\right) \cdot m}}{2 \cdot m} .
$$

To ensure system stability, the real part of these roots must satisfy the following condition:

$$
\operatorname{Re}\left\{s_{1,2}\right\} \leq 0 .
$$

Case 1. If the root is negative,

$$
\begin{gathered}
\left(K_{\mathrm{D}} \cdot K_{f c f}\right)^{2}-4 \cdot m \cdot\left(K_{\mathrm{P}} \cdot K_{f c f}-K_{x}\right)<0 \\
\Longrightarrow \frac{\left(K_{\mathrm{D}} \cdot K_{f c f}\right)^{2}-4 \cdot m \cdot K_{x}}{4 \cdot m \cdot K_{f c f}}>K_{\mathrm{P}}
\end{gathered}
$$

With negative discriminant,

$$
\operatorname{Re}\left\{s_{1,2}\right\}=\frac{-K_{\mathrm{D}} \cdot K_{f c f}}{2 \cdot m} \Longrightarrow K_{\mathrm{D}} \geq 0 .
$$


Case 2. If the root is not negative,

$$
\begin{aligned}
& s_{1} \\
& =\frac{-K_{f c f} \cdot K_{\mathrm{D}}+\sqrt{\left(K_{f c f} \cdot K_{\mathrm{D}}\right)^{2}-4 \cdot\left(K_{f c f} \cdot K_{\mathrm{P}}-K_{x}\right) \cdot m}}{2 \cdot m} \\
& \leq 0, \\
& s_{2} \\
& =\frac{-K_{f c f} \cdot K_{\mathrm{D}}-\sqrt{\left(K_{f c f} \cdot K_{\mathrm{D}}\right)^{2}-4 \cdot\left(K_{f c f} \cdot K_{\mathrm{P}}-K_{x}\right) \cdot m}}{2 \cdot m} \\
& \leq 0 .
\end{aligned}
$$

Adding in members to (25) and (26) the following can be obtained:

$$
\frac{-2 \cdot K_{f c f} \cdot K_{\mathrm{D}}}{2 \cdot m} \leq 0 \Longrightarrow K_{\mathrm{D}} \geq 0
$$

Using (25) the below expression occurs:

$$
\begin{aligned}
& K_{f c f} \cdot K_{\mathrm{D}} \\
& \quad \geq \sqrt{\left(K_{f c f} \cdot K_{\mathrm{D}}\right)^{2}-4 \cdot\left(K_{f c f} \cdot K_{\mathrm{P}}-K_{x}\right) \cdot m} \Longrightarrow \\
& 4 \cdot\left(K_{f c f} \cdot K_{\mathrm{P}}-K_{x}\right) \cdot m \geq 0 \Longrightarrow \\
& K_{\mathrm{P}} \geq \frac{K_{x}}{K_{f c f}} .
\end{aligned}
$$

3.12. Proportional-Integral-Differential Controller (PID). Assuming the existence of proportional-integral-differential controller the system is the following:

$$
\begin{aligned}
& \frac{X}{X^{\prime}} \\
& =\frac{\left(K_{\mathrm{D}} \cdot s^{2}+K_{\mathrm{P}} \cdot s+K_{\mathrm{I}}\right) \cdot K_{f c f}}{m \cdot s^{3}+K_{f c f} \cdot K_{\mathrm{D}} \cdot s^{2}+\left(K_{\mathrm{P}} \cdot K_{f c f}-K_{x}\right) \cdot s+K_{f c f} \cdot K_{\mathrm{I}}} .
\end{aligned}
$$

In the case of marginal stability the poles of the system are zero:

$$
\operatorname{Re}\left\{s_{1,2,3}\right\}=0 \text {. }
$$

Based on this treaty, the stability of the system is proven after satisfying the following conditions:

$$
\begin{aligned}
& K_{I} \geq 0, \\
& K_{\mathrm{P}} \geq \frac{K_{x}}{K_{f c f}}, \\
& K_{\mathrm{D}} \geq 0 .
\end{aligned}
$$

\section{Simulation Results}

In this paragraph, the system is simulated in terms of $\mathrm{P}$, PD, and PID controllers for which control stability of the system can be guaranteed. For better results, the model as well as stability provided by each controller has been tested by introducing white noise. The white noise in the system simulates external disturbances which can adversely affect the system. Its form is ideal and the noise is independent of frequency as its spectrum has the same constant value for all frequencies. The simulated system is shown in Figure 3.

For the procedure testing of controllers white noise is introduced with two levels of noise, 0.01 volts and 0.001 volts.

From the below experimental data it is shown that optimal combination is achieved by PID controller. Using the PID controller a very small displacement of the rotor from its equilibrium position is accomplished under the influence of white noise. Simultaneously, the values of the control current remain small at desired levels. These levels ensure that the magnetic bearings do not influence the neighboring magnetic fields. A further advantage of the controller, known from the theory, is the most direct smoothing achieved in the system because of the presence of integral controller.

4.1. $P$ Controller. Initially setting the proportional gain to 8875.1, the results obtained are shown in Figures 4 and 5.

In Figures 4 and 5 the position of the rotor is shown. It has been observed that values cannot be accepted as they lead to large control currents and large values of the divergence of the shaft.

For optimization of the controller, the proportional gain has been increased to 12000; results for the same noise levels are presented in Figures 6 and 7.

Figures 6 and 7 present the position of the shaft of the bearing. It has been observed that values cannot be accepted as they lead to large control currents. These large control current values presented in $\mathrm{P}$ controller could possibly create a fairly forcible magnetic field, which could adversely affect the magnetic field of the machine creating the movement of the rotor.

4.2. PD Controller. During the same procedure we set the proportional gain to 12.2083 and the differential gain to 1.9875. For these gain values, results are presented in Figures 8 and 9.

Figures 8 and 9 correspond as well in the position of the rotor center with respect to the bearing center. It has been observed that values cannot be accepted as they lead to large values of the divergence of the shaft. To increment the response speed of the controller, the proportional gain has been increased to the value of 192.8569 and the relevant differential gain to a value of 7.8867. For these values the following results in Figures 10 and 11 are obtained.

From Figures 10 and 11 results the fact that the values correspond to the rotor position can be accepted.

4.3. PID Controller. At the end of the test procedure the corresponding gains of PID controller were defined which are 


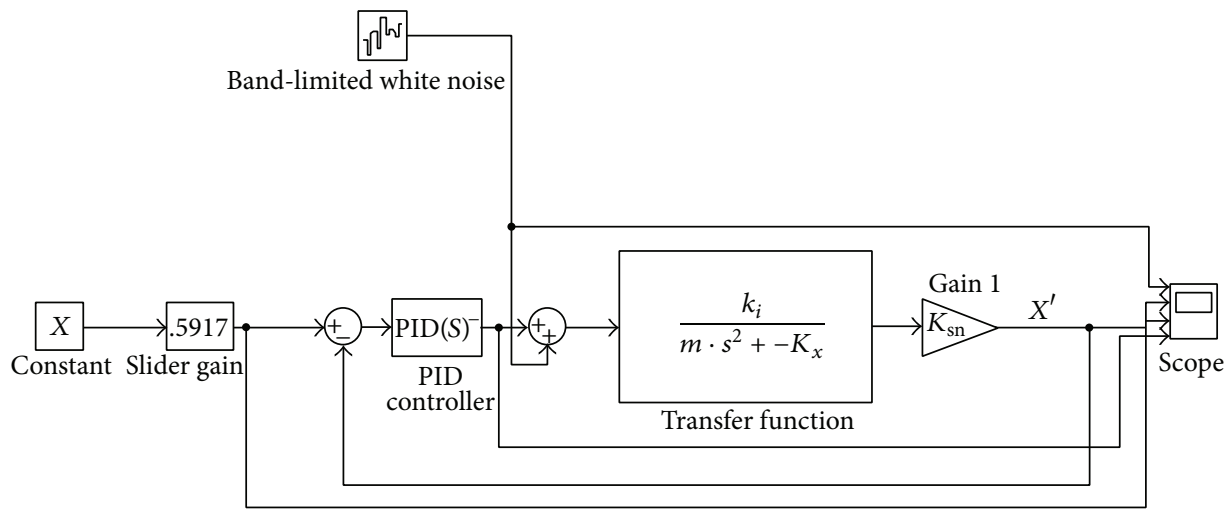

FIgURE 3: Simulation system.
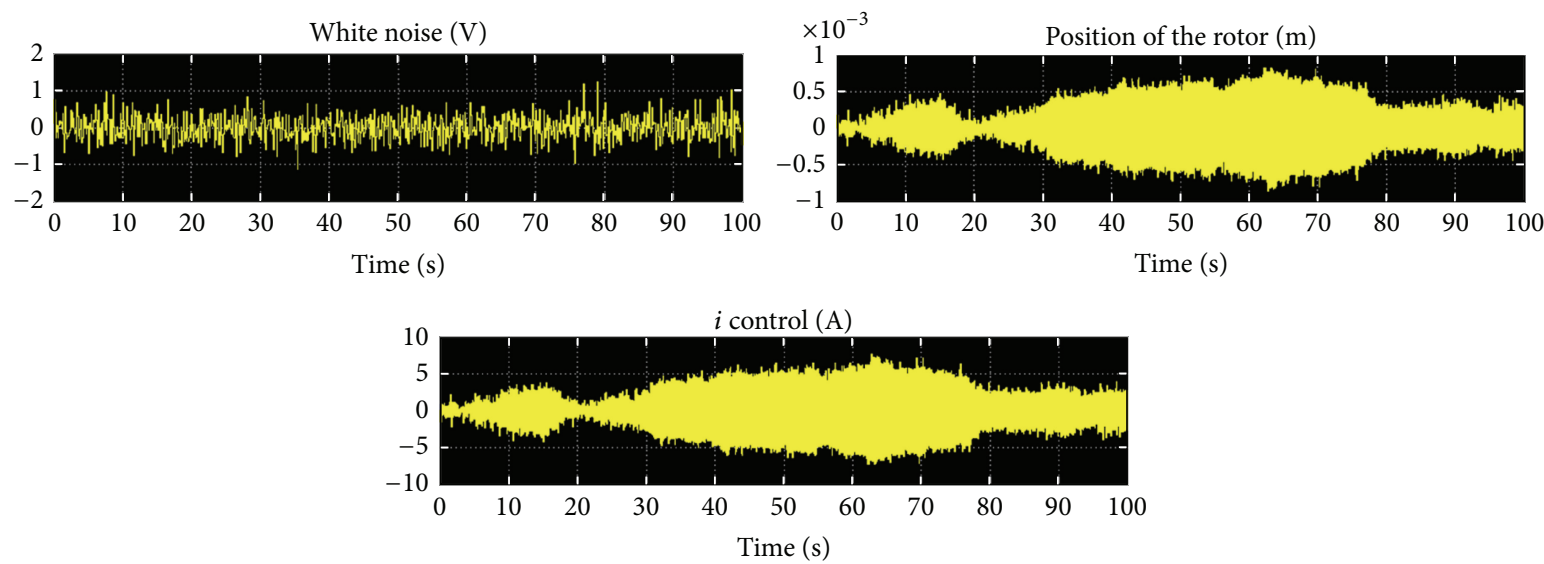

Figure 4: Response with P controller with proportional gain of 8875.1 and white noise of 0.01 volts.
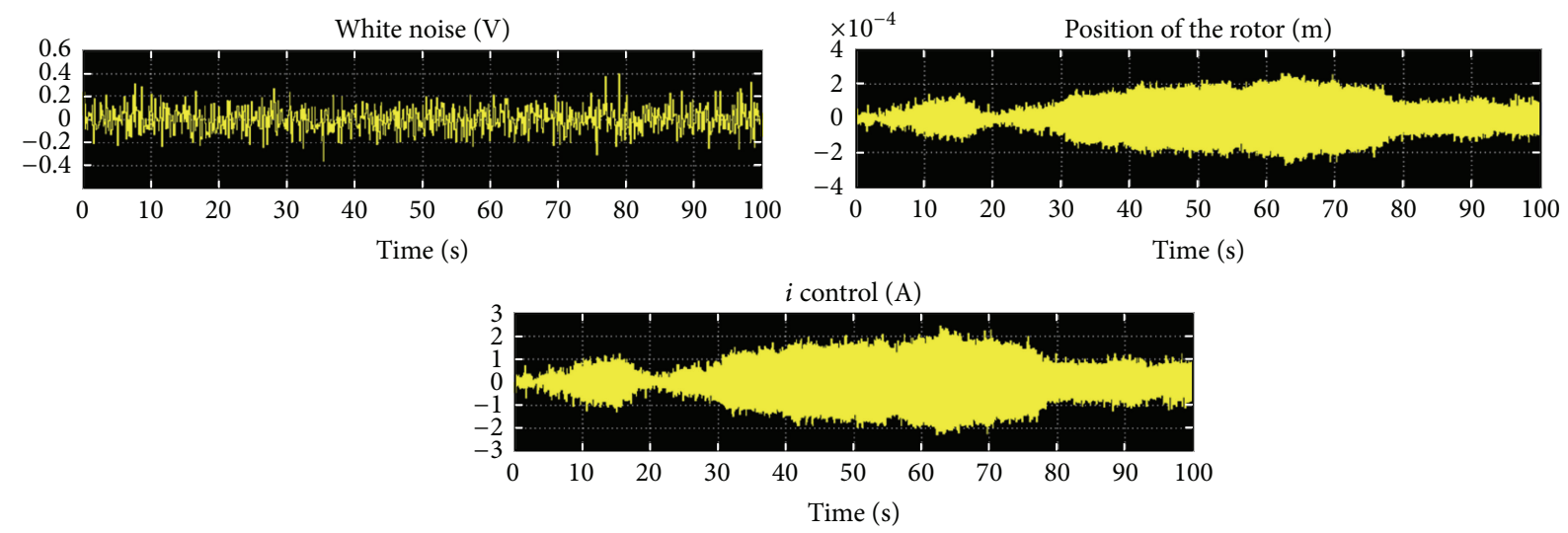

FIGURE 5: System response with P controller with proportional gain of 8875.1 and white noise of 0.001 volts.

for the proportional gain 22.1426, for the integral gain 23.2457, and for the differential gain 283.4574. The results are shown in Figures 12 and 13.

Also form Figures 12 and 13 the obtained values could not be accepted. In an effort to optimize the controller, the gains were changed. The corresponding values have occurred: (i) of the proportional gain as 319.0187 , (ii) of the integral gain as 1273.2977, and (iii) of the differential gain as 7.2565.
Sequentially, the obtained results are shown in Figures 14 and 15.

\section{Control Investigation Using Experimental Data}

After choosing a PID controller that satisfies the stability criteria while giving a satisfactory response rate, the system 

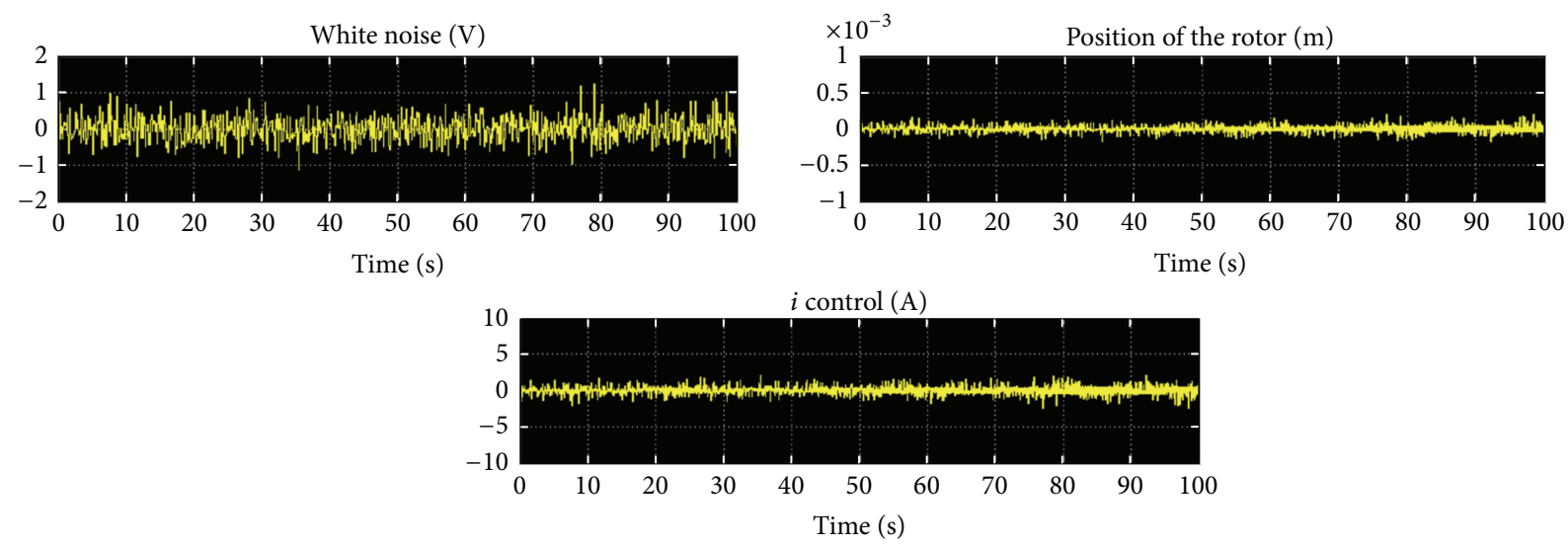

FIGURE 6: System response with P controller with proportional gain of 12000 and white noise of 0.01 volts.
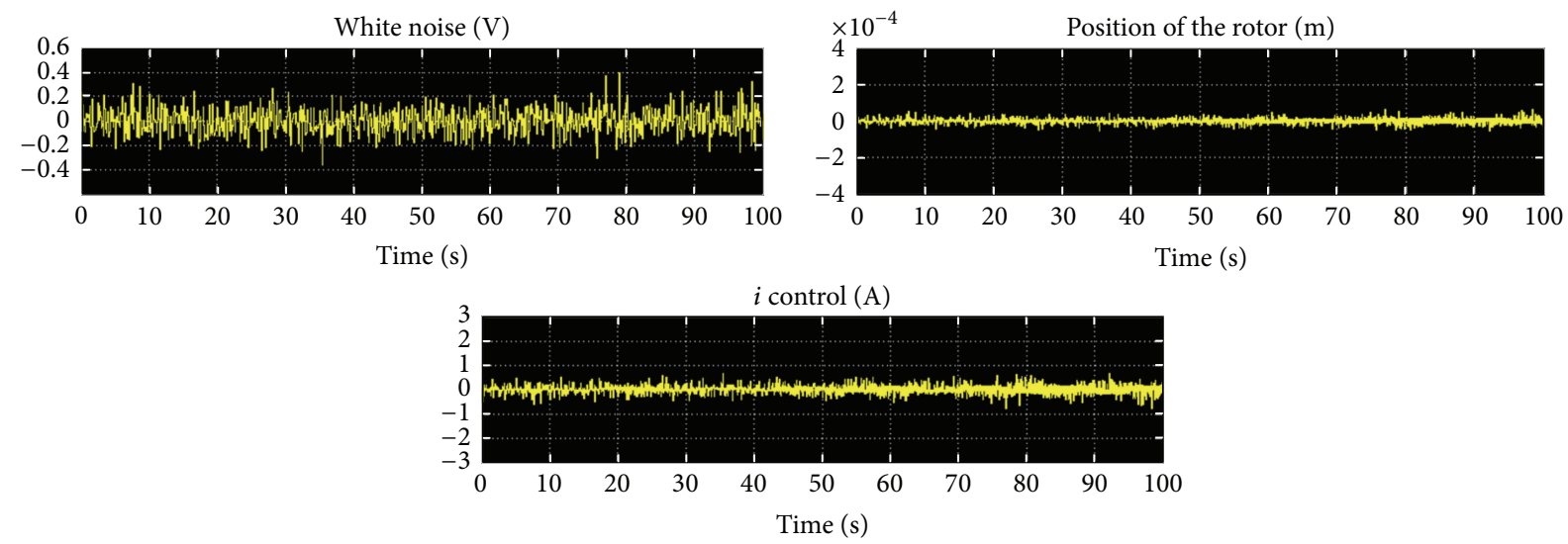

FiguRE 7: System response with P controller with proportional gain of 12000 and white noise of 0.001 volts.
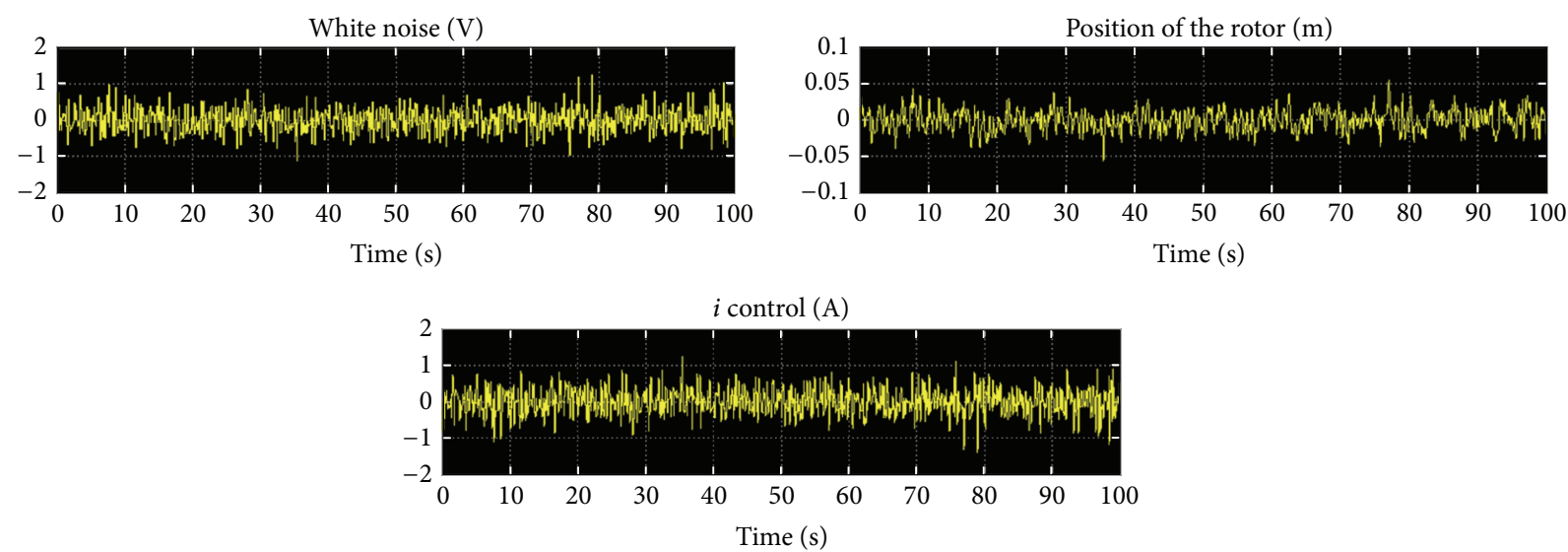

FIGURE 8: System response with PD controller with proportional gain of 12.2083 and gifferential gain of 1.9875 and white noise of 0.01 volts.

has been tested using experimental noise data [7]. This data consists of recorded noise in a range of 0.0048 volts. The PID parameters were found for the proportional gain to be 319.0187, for the integral gain to be 1273.2977, and for the differential gain to be 7.2565. Several values have been tested for the gains and corresponding curves of reference tracking. The above values of gains have been selected as they give faster response with low current. The faster response which has been chosen is shown in Figure 18. This figure shows that the rise time and the recovery time are very small (rise time $<$ $0.002 \mathrm{sec}$, recovery time $<0.015 \mathrm{sec}$ ); simultaneously steadystate gain is very small. The results corresponding to the above PID values are shown in Figures 16 and 17.

In the next step a fastest controller must be found. So, the following PID controller was constructed, with the following reference tracking which as it is shown in Figure 18. 

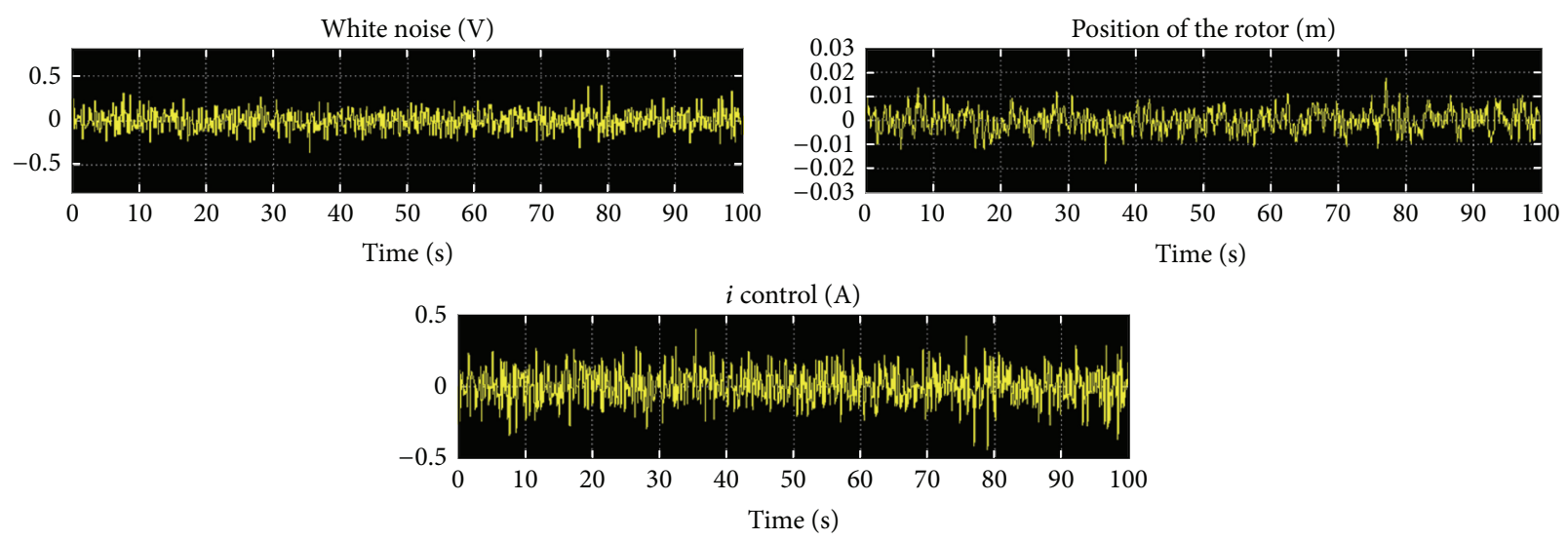

FIGURE 9: System response with PD controller with proportional gain of 12.2083 and differential gain of 1.9875 and white noise of 0.001 volts.
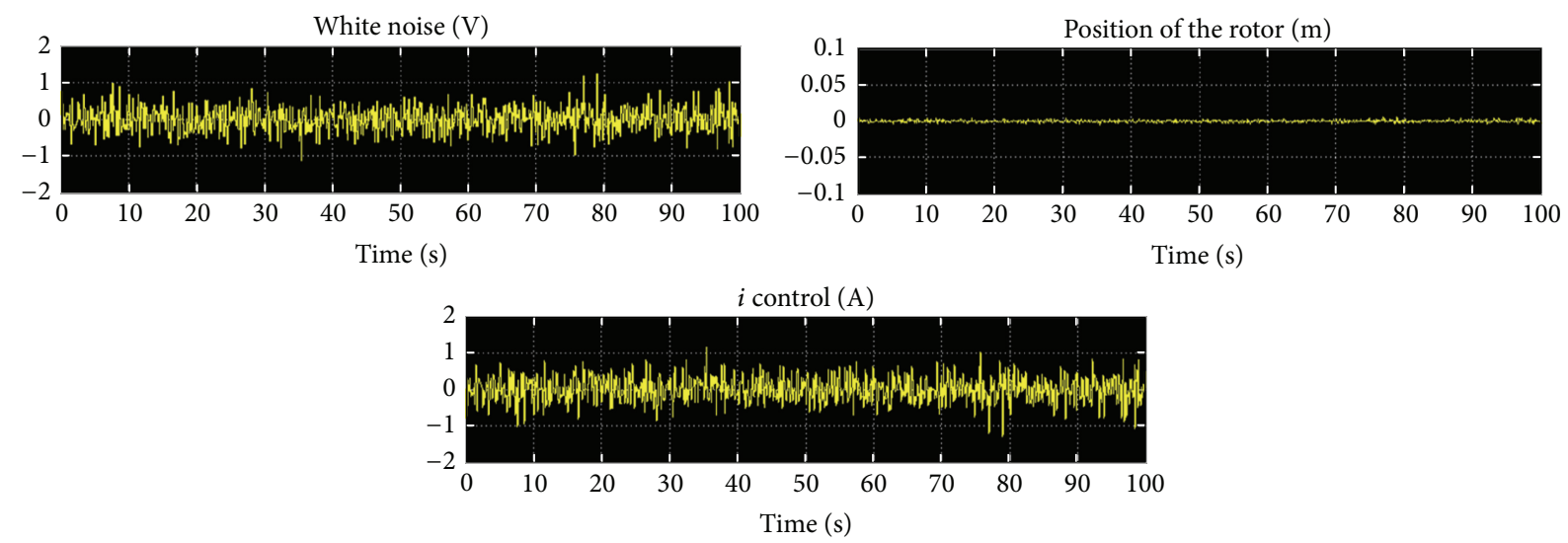

FIGURE 10: System response with PD controller with proportional gain of 192.8569 and differential gain of 7.8867 and white noise of 0.01 volts.

The proportional gain is 1526.6269 , the integral gain is 13330.5096, and the differential gain is 15.8724. Using the above PID values, the system response is shown in Figure 19.

It is depicted from Figure 19 that the proposed PID values lead to a constant gain and relative small control currents while the rotor center remains low. So, these PID values can be considered as suitable.

5.1. System Stability. The stability of the system can also be proved by the mathematical study of the transfer function of the closed loop system with the above controller PID values:

$$
\begin{aligned}
& \frac{X}{X^{\prime}} \\
& =\frac{\left[s^{2}\left(K_{\mathrm{P}}+N \cdot K_{\mathrm{D}}\right)+s\left(K_{\mathrm{P}} \cdot N+K_{\mathrm{I}}\right)+K_{\mathrm{I}} \cdot N\right] \cdot K_{f c f} \cdot k_{\mathrm{sn}}}{m \cdot s^{4}+N \cdot m \cdot s^{3}+\left(\left(K_{\mathrm{P}}+N \cdot K_{\mathrm{D}}\right) \cdot K_{f c f} \cdot k_{\mathrm{sn}}-k_{x}\right) s^{2}+\left(\left(K_{\mathrm{P}} \cdot N+K_{\mathrm{I}}\right) \cdot K_{f c f} \cdot k_{\mathrm{sn}}-k_{x} \cdot N\right) \cdot s+K_{f c f} \cdot K_{\mathrm{I}} \cdot N \cdot k_{\mathrm{sn}}},
\end{aligned}
$$

where the proportional gain is 1526.6269 , the integral gain is 13330.5096 , and the differential gain is 15.8724 .

The poles of the above transfer function are

$$
\begin{aligned}
& P 1=-9.71450, \\
& P 2=-90.13387,
\end{aligned}
$$

$$
\begin{aligned}
& P 3=-1128.92409+1177.08749 * i, \\
& P 4=-1128.92409-1177.08749 * i .
\end{aligned}
$$

The transfer function which appears in (32) has 4 poles, of which 2 are real and 2 are complex. All of them have negative real part, which means that they are in the left half-plane. This is a necessary and sufficient condition for 

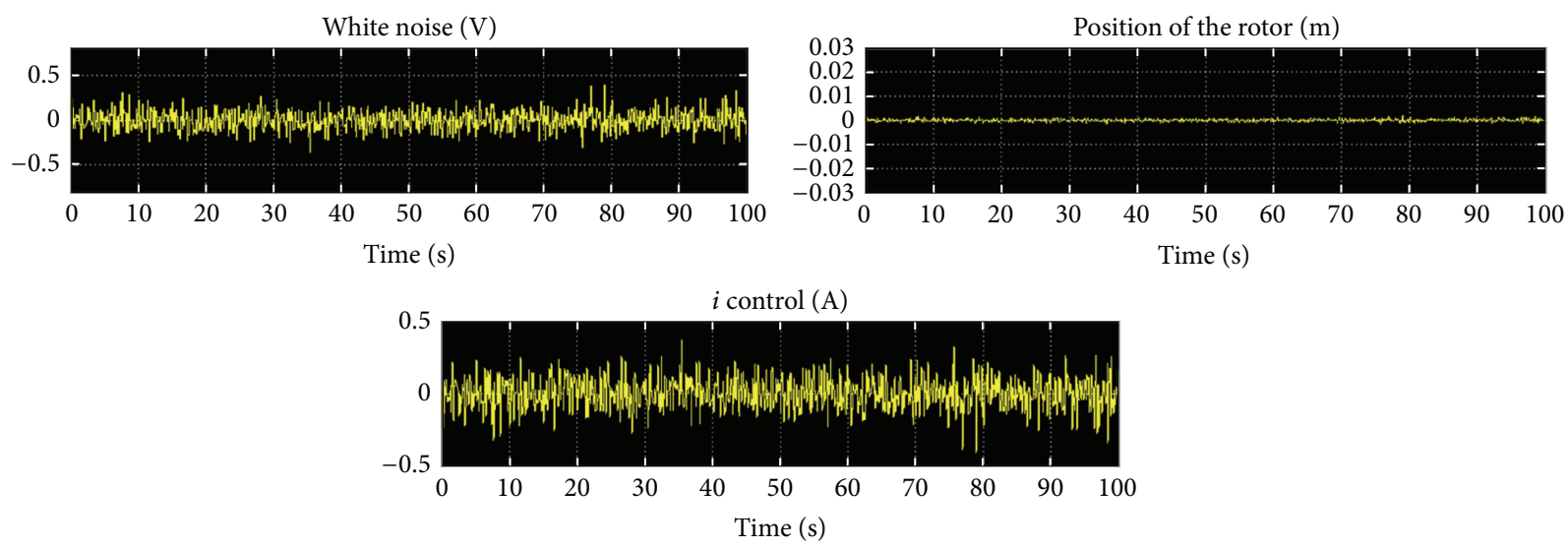

FIGURE 11: System response with PD controller with proportional gain of 192.8569 and differential gain of 7.8867 and white noise of 0.001 volts.
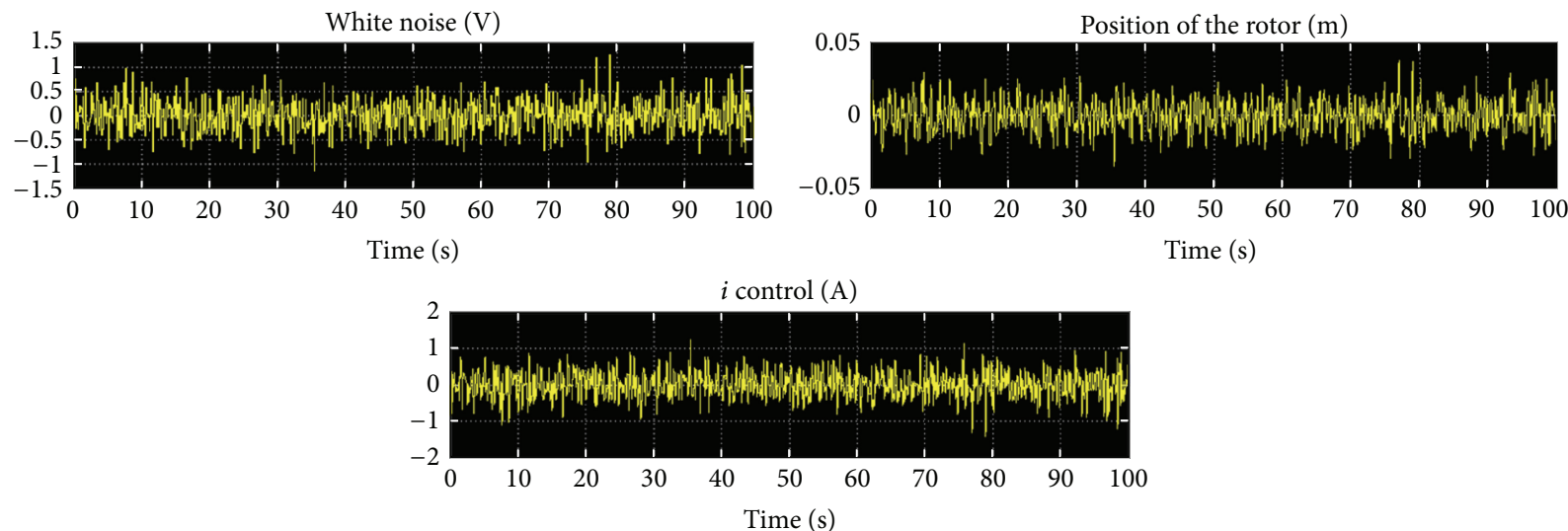

FIGURE 12: System response with PID controller with proportional gain of 22.1426, integral gain of 23.2457, and differential gain of 283.4574 and white noise of 0.01 volts.
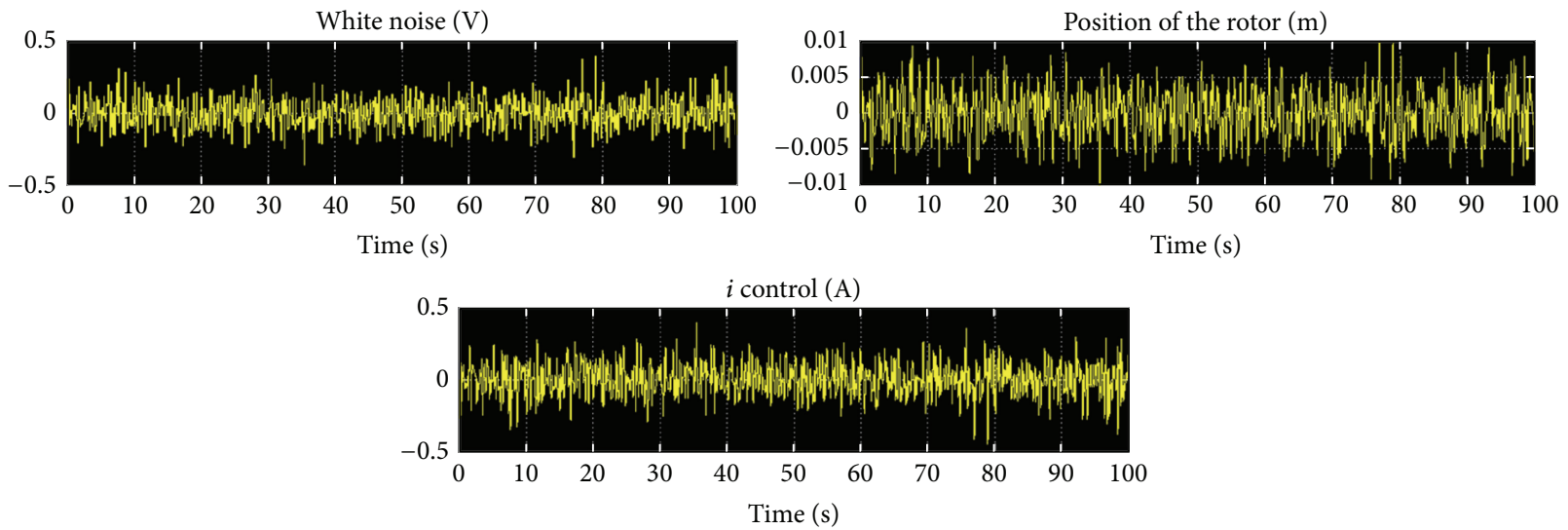

FIGURE 13: System response with PID controller with proportional gain of 22.1426, integral gain of 23.2457, and differential gain of 283.4574 and white noise of 0.001 volts.

system stability. Observing the real poles of the system, it is perceived that the system has quick response as these two poles have not an imaginary part $(P 1=-9.7145$, $P 2=-90.13387)$. Simultaneously the two complex poles of the system have small ratio of the real to the imaginary part. This helps to cancel the oscillation of the system. All the above are perceived by observing Figure 19 which is the system response with PID controller. 

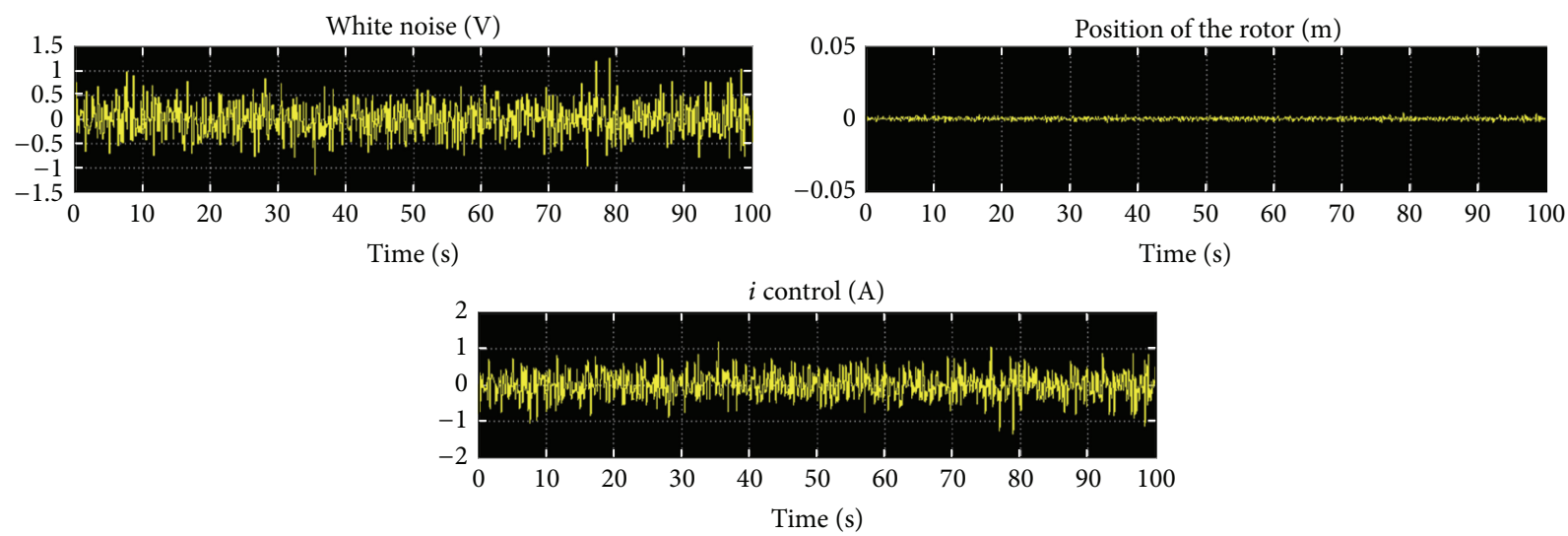

FIGURE 14: System response with PID controller with proportional gain of 319.0187, integral gain of 1273.2977, and differential gain of 7.2565 and white noise of 0.01 volts.
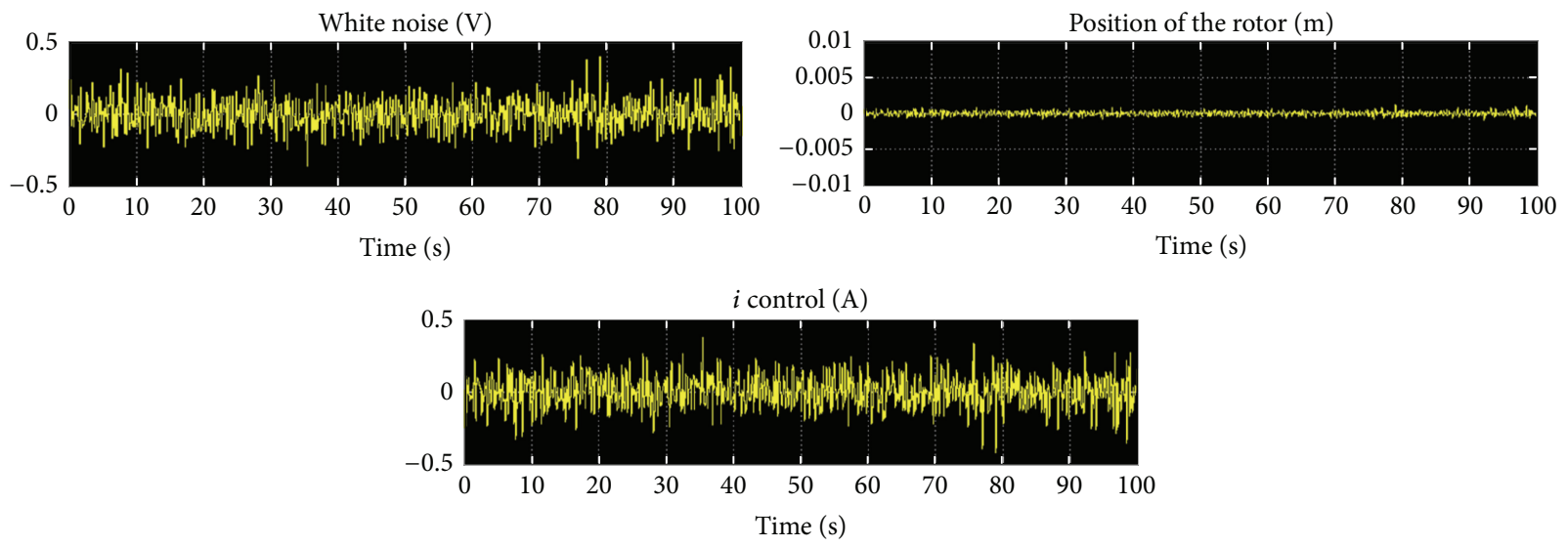

FIGURE 15: System response with PID controller with proportional gain of 319.0187, integral gain of 1273.2977, and differential gain of 7.2565 and white noise of 0.001 volts.

\section{Conclusion}

In this paper the control of a linear model of a magnetic bearing is presented. The equations of the closed loop systems with the individual linear controllers have been analyzed and the conditions for control stability have been investigated. From the above analysis, the control performance of the magnetic bearing has been studied with a linear model and three types of controllers, P, PD, and PID. Subsequently, these three controllers have been simulated and characteristic results have been derived with the presence of white noise. Then, in order to avoid large values in the associated gains, while keeping the system within certain limits, the PID controller has been selected. For this purpose the corresponding gains have been selected in order to satisfy the required boundary conditions. Then the specific controller has been tested through simulation. Finally, the mathematical model was studied and the stability of the controller was proved.

\section{Nomenclature}

D: Derivative

$F_{1}$ : Force from electromagnet

$g$ : Acceleration of gravity
I: Integral

$I_{\text {bias }}:$ Current bias

$K_{\mathrm{D}}: \quad$ Derivative gain

$K_{\mathrm{I}}: \quad$ Integral gain

$K_{f c f}:$ Force-current factor

$K_{\mathrm{P}}: \quad$ Proportional gain

$K_{x}: \quad$ Force-displacement factor (stiffness coefficients)

$l: \quad$ Stack length

$L_{0}: \quad$ Nominal inductance

$m$ : $\quad$ Mass of shaft

$N$ : Number of turns

P: Proportional

$p: \quad$ Number of pole bearings

PD: Proportional derivative

PI: Proportional integral

PID: Proportional integral derivative

S: $\quad$ Cross-sectional area of flux path

$W: \quad$ Weight of shaft

$W \times l$ : Gasket-gap magnet shaft

$\theta_{t}$ : Angle between shaft and electromagnet (Figure 1), $\theta_{t}=25 \mathrm{deg}$

$\mu_{0}: \quad$ Permeability of free space. 

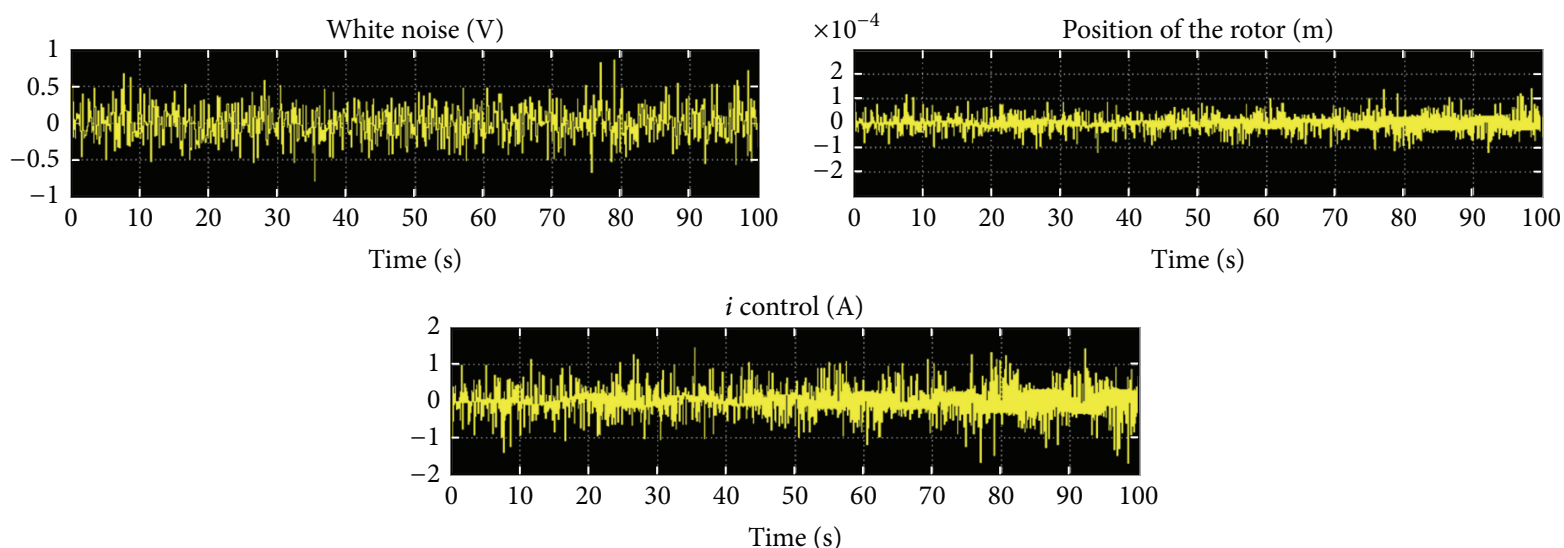

FIGURE 16: System response with PID controller with proportional gain of 319.0187, integral gain of 1273.2977, and differential gain of 7.2565 and white noise of 0.001 volts.
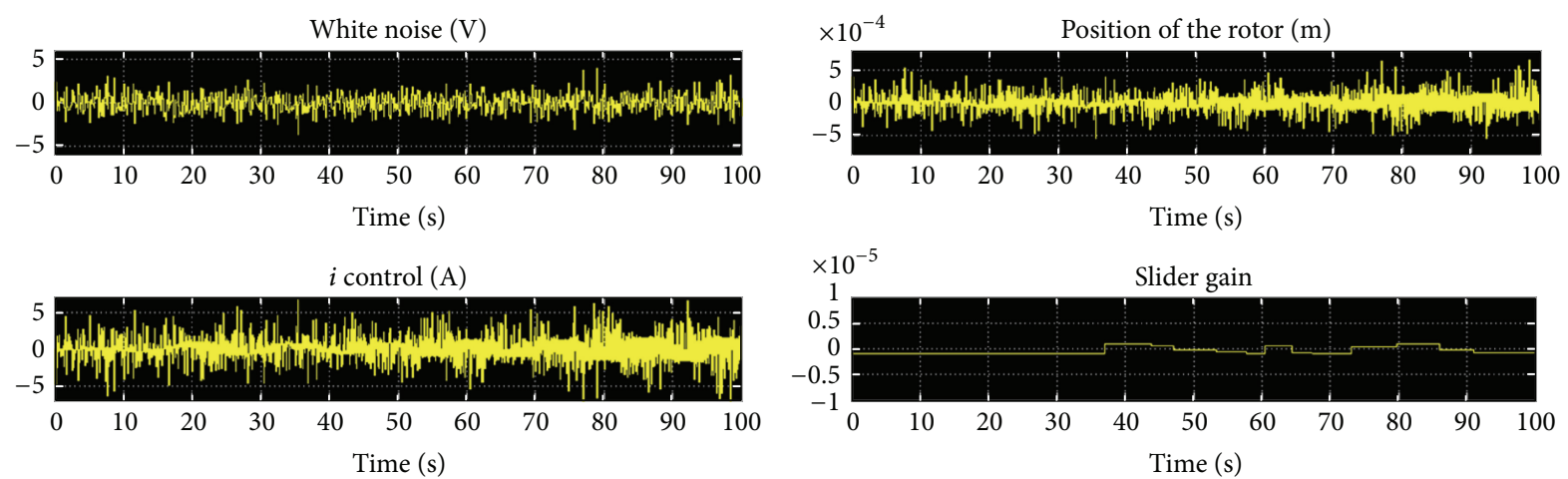

FIGURE 17: System response to enforced changes of the $x$ position. System with PID controller with proportional gain of 319.0187, integral gain of 1273.2977, and differential gain of 7.2565 and white noise of 0.001 volts.

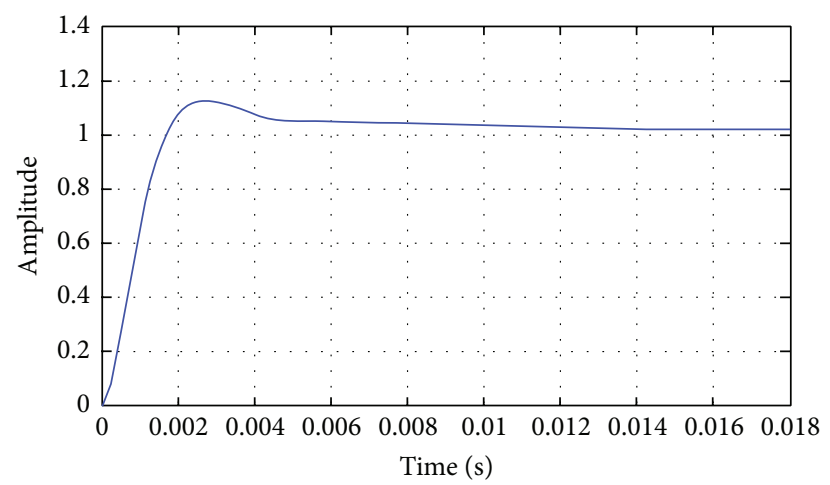

- Block response

— Tuned response

FIGURE 18: Reference tracking for PID controller. 

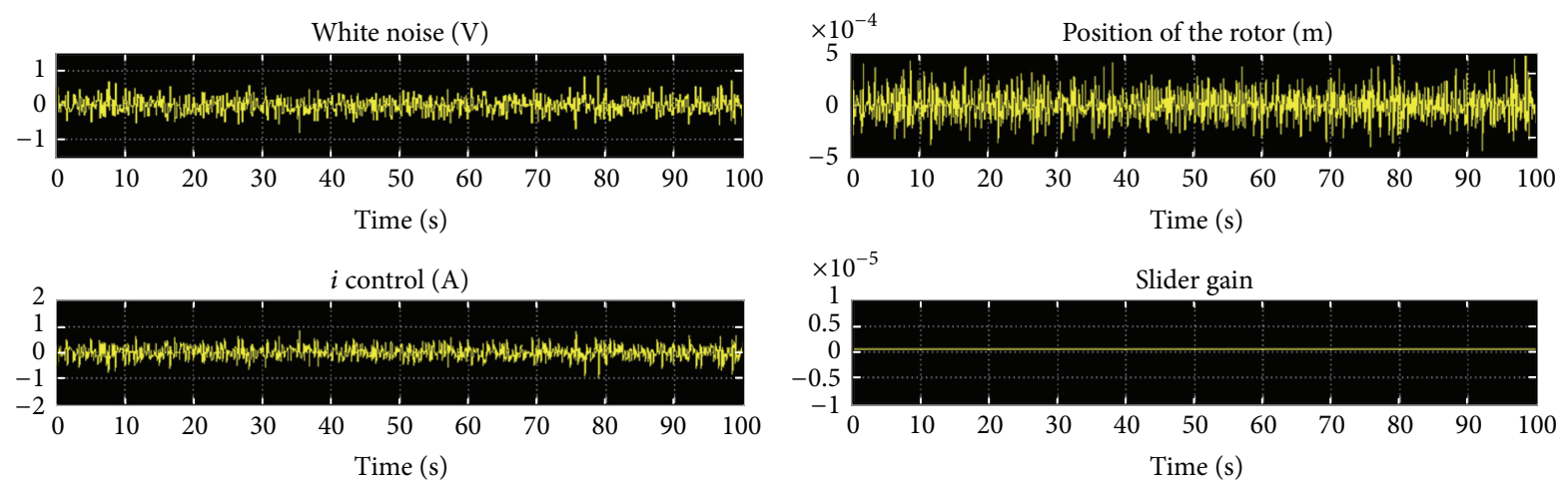

FIGURE 19: System response with PID controller with proportional gain of 1526.6269, integral gain 13330.5096, and differential gain of 15.8724 and white noise of 0.01 volts.

\section{Conflict of Interests}

The authors declare that there is no conflict of interests regarding the publication of this paper.

\section{References}

[1] E. J. Gunter, "Lund's contribution to rotor stability: the indispensable and fundamental basis of modern compressor design," Journal of Vibration and Acoustics, vol. 125, no. 4, pp. 462-470, 2003.

[2] R. Tiwari, A. W. Lees, and M. I. Friswell, "Identification of dynamic bearing parameters: a review," The Shock and Vibration Digest, vol. 36, no. 2, pp. 99-124, 2004.

[3] G. Schweitzer and E. H. Maslen, Magnetic Bearings Theory, Design and Application to Rotating Machinery, Springer, Berlin, Germany, 2009.

[4] S.-L. Chen, S.-Y. Hsu, P.-L. Wang, and D. Juang, "A feasibility study of a bearingless motor based on three-pole active magnetic bearing," International Journal of Automation and Smart Technology, vol. 2, no. 2, pp. 133-140, 2012.

[5] L. Dong and S. You, "Adaptive control of an active magnetic bearing with external disturbance," ISA Transactions, vol. 53, no. 5, pp. 1410-1419, 2014.

[6] A. Chiba, T. Fukao, and O. Ichikawa, Magnetic Bearings and Bearingless Drives, Elsevier, Amsterdam, The Netherlands, 2005.

[7] M. G. Farmakopoulos, E. K. Loghis, P. G. Nikolakopoulos, N. I. Xiros, and C. A. Papadopoulos, "Modeling and control of the electrical actuation system of an active hydromagnetic journal bearing (AHJB)," in Proceedings of the International Mechanical Engineering Congress and Exposition (ASME '14), Montreal, Canada, November 2014.

[8] B. Polajžer, J. Ritonja, G. Štumberger, D. Dolinar, and J.P. Lecointe, "Decentralized PI/PD position control for active magnetic bearings," Electrical Engineering, vol. 89, no. 1, pp. 5359, 2006.

[9] G. Zames, "Feedback and optimal sensitivity: model reference transformations, multiplicative seminorms, and approximate inverses," IEEE Transactions on Automatic Control, vol. 26, no. 2, pp. 301-320, 1981.

[10] R. Herzog and H. Bleuler, "Stiff AMB control using an Hinfinity approach," in Proceedings of the Second International
Symposium on Magnetic Bearings, pp. 343-348, Tokyo, Japan, July 1990.

[11] M. Fujita, F. Matsumuro, and M. Shimizu, " $\mathrm{H}_{\infty}$ robust control design for a magnetic suspension system," in Proceedings of the 2nd International Symposium on Magnetic Bearings, pp. 349356, Tokyo, Japan, July 1990.

[12] W. de Boer, Active magnetic bearings: modelling and control of a five degrees of freedom rotor [M.S. thesis], Eindhoven University of Technology, Eindhoven, The Netherlands, 1998.

[13] G. Schweitzer, "Active magnetic bearings-chances and limitations," in Proceedings of the IFToMM 6th International Conference on Rotor Dynamics, vol. 1, pp. 1-14, Sydney, Australia, September-October 2002.

[14] M. Saffarzadeh, A. Delavarkhalafi, and Z. Nikoueinezhad, "Numerical method for solving optimal control problem of stochastic Volterra integral equations using block pulse functions," The Journal of Mathematics and Computer Science, vol. 11, pp. 22-36, 2014.

[15] P. Lopes dos Santos, J. A. Ramos, and J. L. Martins de Carvalho, "Identification of linear parameter varying systems using an iterative deterministic-stochastic subspace approach," in Proceedings of the European Control Conference, pp. 4867-4873, IEEE, Kos, Greece, July 2007.

[16] P. Denver Timothy, V. Brown Gerald, and H. Jansen Ralph, "Estimator based controller for high speed flywheel magnetic bearing system," NASA Internal Report NASA/TM-2002211795, 2002.

[17] T. Zhang, Control of magnetic bearings in wind turbines [M.S. thesis], Delft University of Technology, Delft, The Netherlands, 2010. 

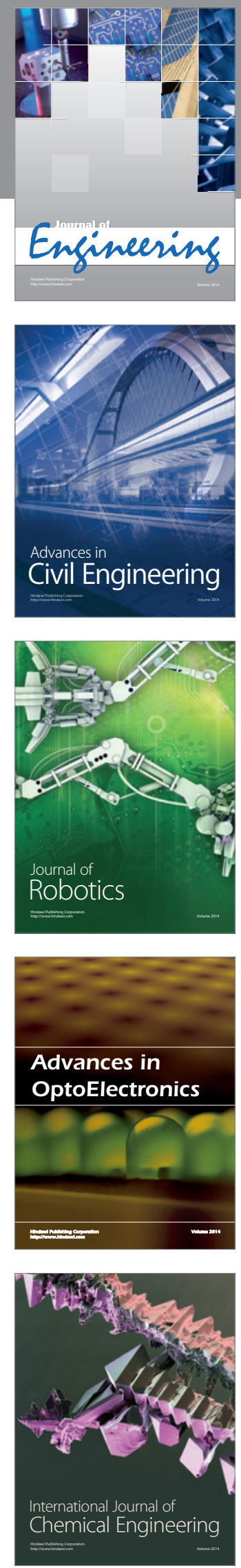

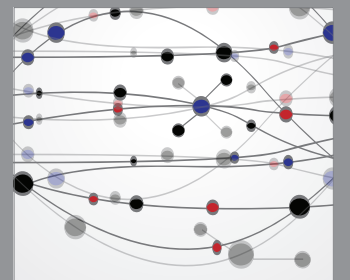

The Scientific World Journal
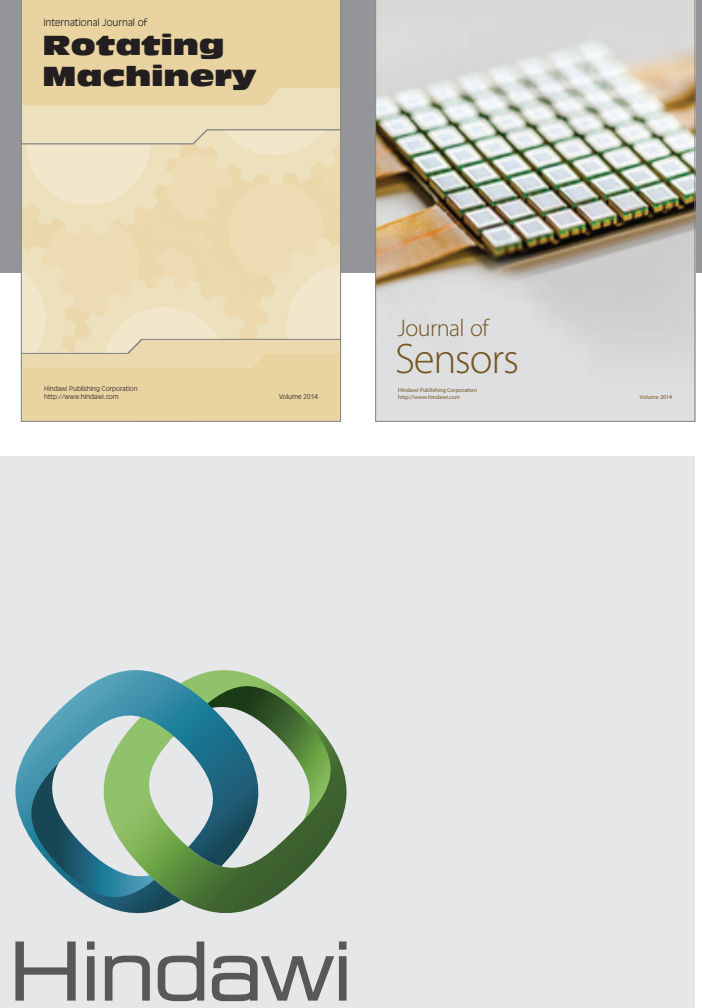

Submit your manuscripts at http://www.hindawi.com
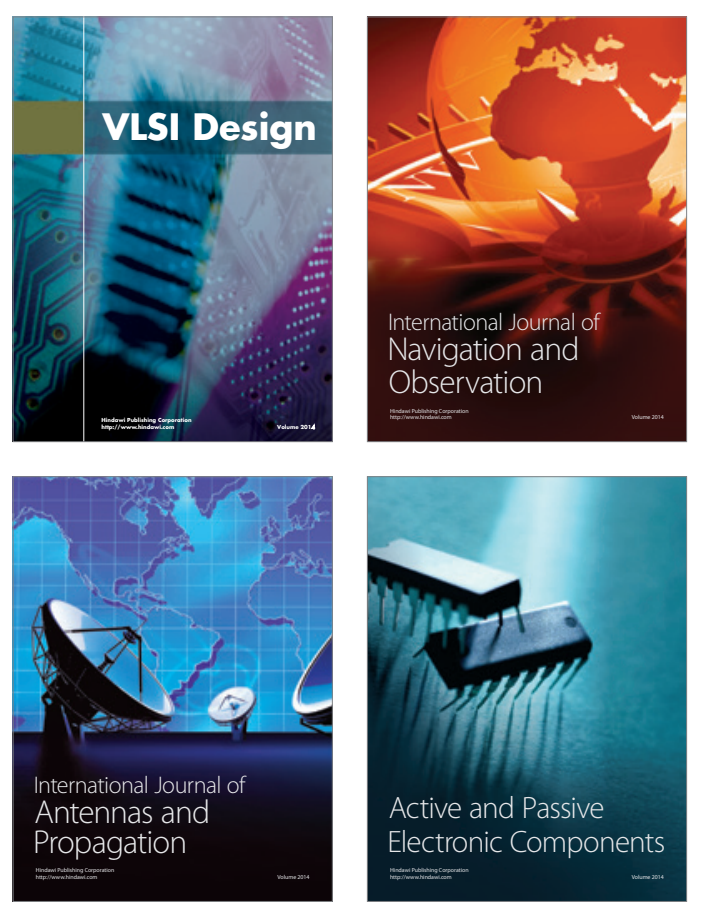
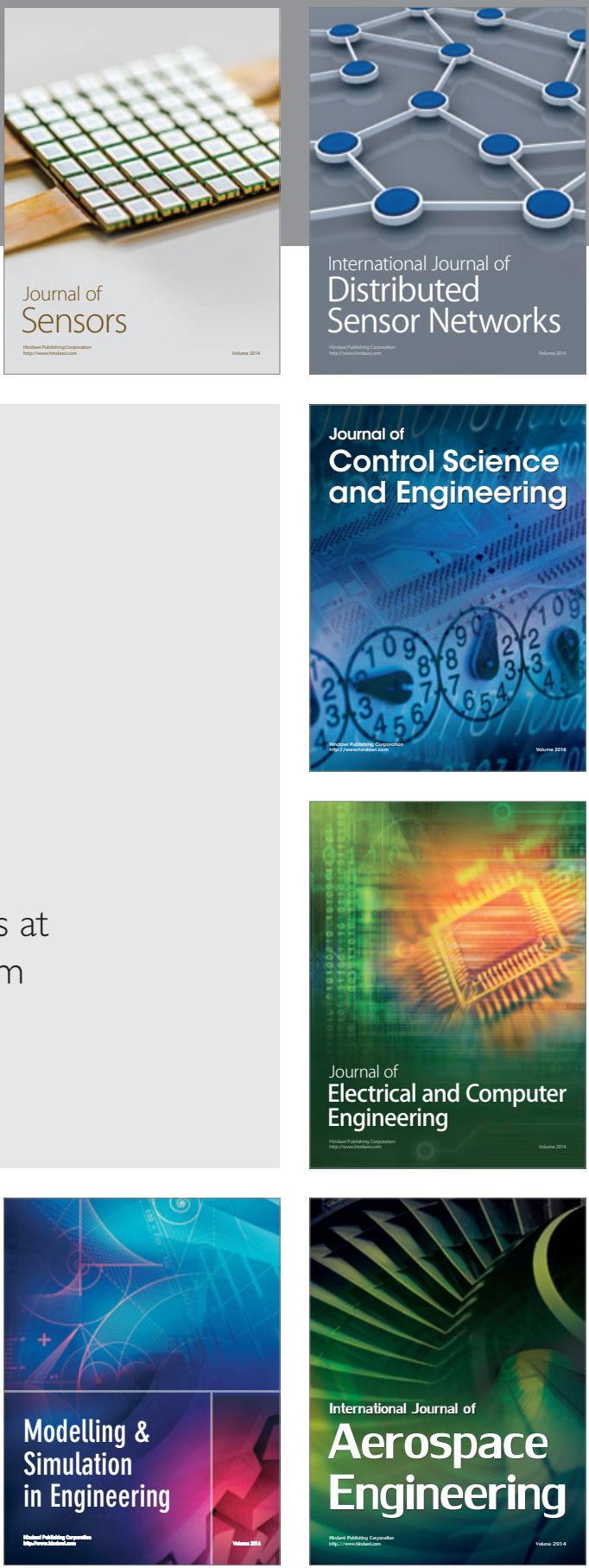

Journal of

Control Science

and Engineering
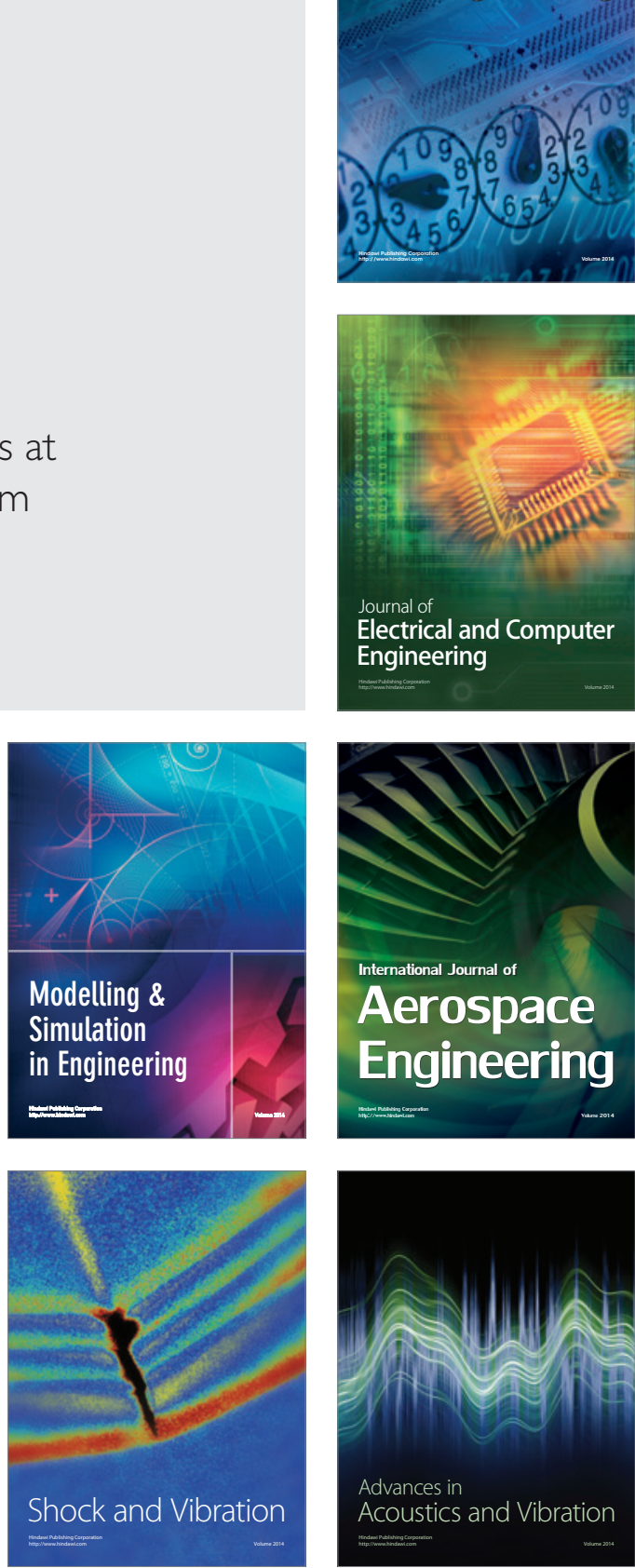